\title{
Correction to: Modification of hyperbranched hemicellulose polymer and its application in adsorbing acid dyes
}

\author{
Linya Zhang $(\mathbb{D} \cdot$ Wei Xue $\cdot$ Limin Gu
}

Published online: 4 July 2019

(C) Springer Nature B.V. 2019

Correction to: Cellulose (2019) 26:5583-5601

https://doi.org/10.1007/s10570-019-02483-0

In the original publication of the article, the graphical abstract and Scheme 1(a) and Scheme 1(b) were published incorrectly. The correct version is provided in this correction. 
The graphical abstract was revised as follows:

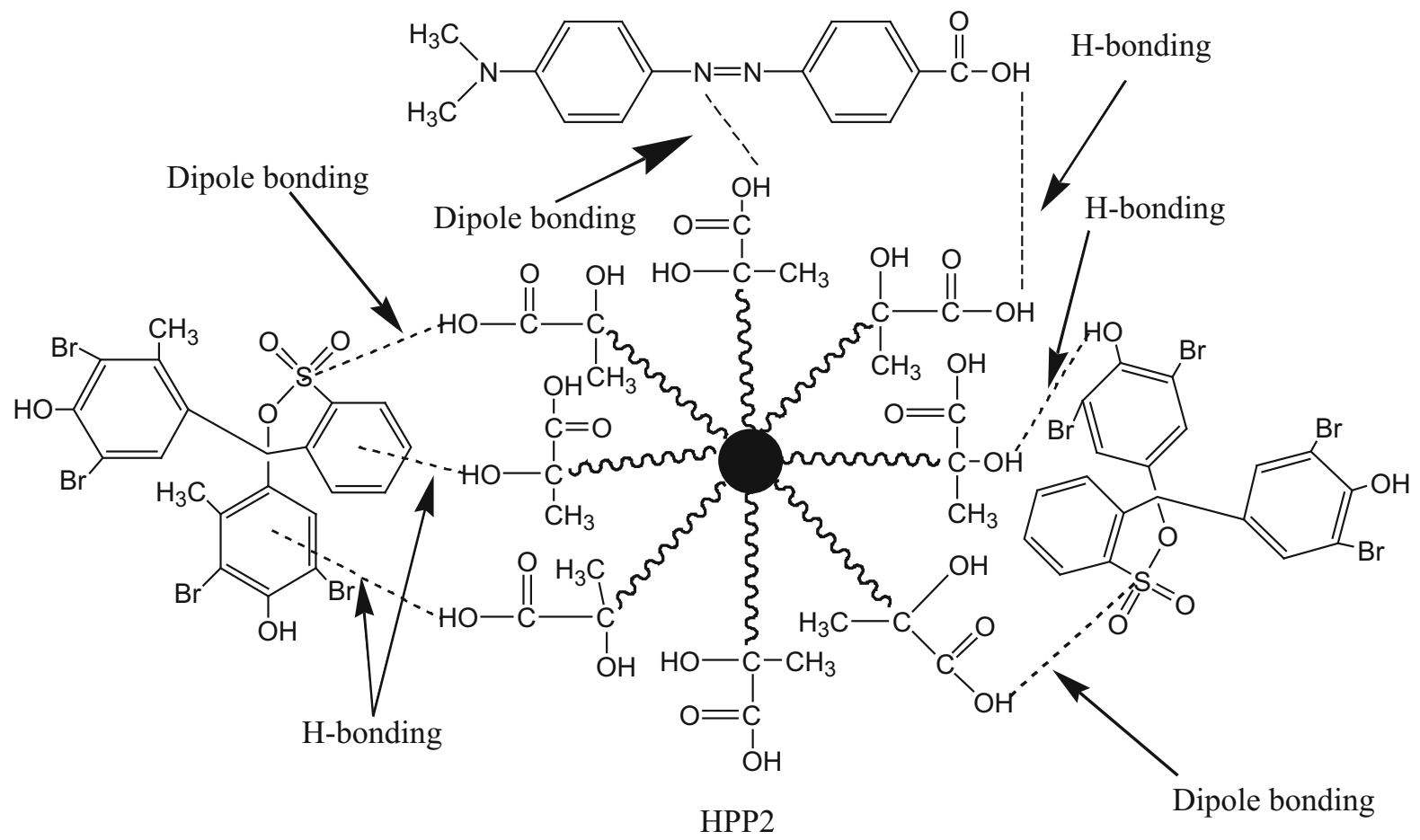

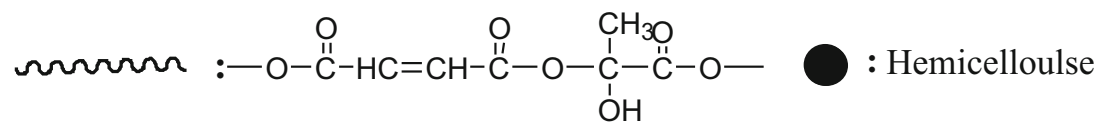

The Scheme 1(a) and Scheme 1(b) were revised as follows:

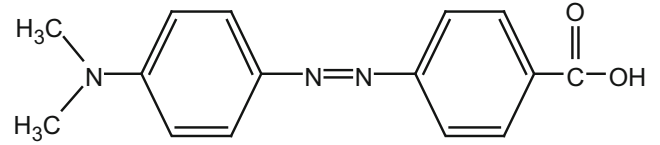

Methyl Red

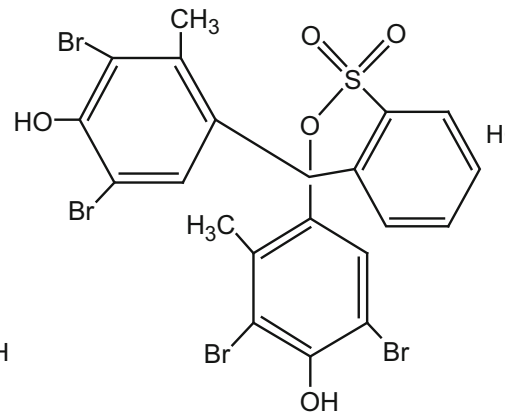

Bromocresol Green<smiles>O=S1(=O)OC(c2cc(Br)c(O)c(Br)c2)(c2cc(Br)c(O)c(Br)c2)c2ccccc21</smiles>

Bromophenol Blue

Scheme 1(a) The structure of methyl red dye, bromocresol green dye and bromophenol blue dye 


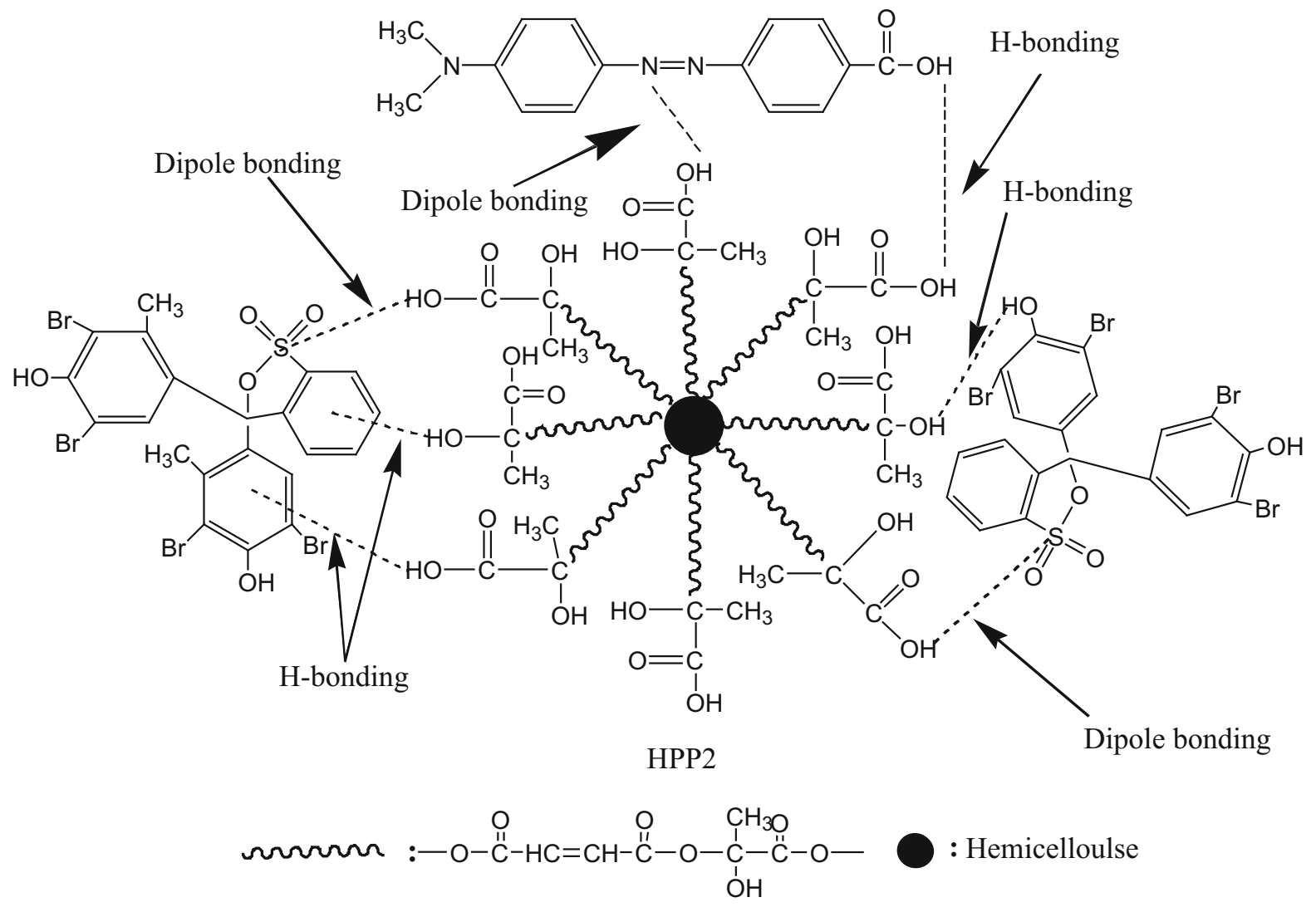

Scheme 1(b) The modified hyperbranched hemicellulose polymer adsorbed methyl red dye, bromocresol green dye and bromophenol blue dye

Publisher's Note Springer Nature remains neutral with regard to jurisdictional claims in published maps and institutional affiliations. 